\title{
Ecological and Economic Risks of Fire Protection of Warehouses and Tank Parks
}

\author{
Evgeniy Degaev ${ }^{1 *}$, Anton Orlov ${ }^{1}$, Pierre El Haddad ${ }^{2}$, Alexander Pleshivtsev ${ }^{1}$ \\ ${ }^{1}$ Moscow State University of Civil Engineering, Yaroslavskoe shosse 26, Moscow, 129337, Russia \\ ${ }^{2}$ Saint-Joseph University, Beirut \\ ${ }^{2}$ Lyon III University, France
}

\begin{abstract}
The article deals with fire extinguishing methods at warehouse facilities, environmental and economic risks of their application and ways of how to minimize possible impacts. This is due to the fact that fire extinguishing agents used are not ecologically safe and they damage the environment and humans. Analysis of existing fire protection systems for tanks has shown that all extinguishing methods have drawbacks and are mainly environmentally harmful.
\end{abstract}

\section{Introduction}

Construction facilities are most often exposed to various risks, the most dangerous of which are fire risks. Warehouse premises, pumping stations and tank farms have been and remain the most fire-hazardous facilities.

In spite of introducing advanced fire extinguishing technologies, combating fire risks at capital construction warehouse facilities remains an urgent and very pressing problem. Recent years have shown that major fires and disasters cannot be prevented.

\section{Materials and Methods}

The paper uses methods of scientific observation, comparison, personal experience and analysis. Publicly available information on major fires in Russia and in the world, their fire extinguishing systems, operating conditions and accident impacts were studied. Specifically, fire in 2012 at the Amuay refinery, part of the Paraguana Refinery Complex, was the largest man-made disaster in the history of Petroleos de Venezuela (Fig. 1). Over 220 firefighters were involved in extinguishing operation. The flame was extinguished only in three days. Death toll mounted to 51 [1-5].

Large-scale fires happen in Russia too. In 2014, there was an explosion at the LukoilUsinskneftegaz Local Production Plant area in the Komi Republic - an oil tank exploded followed by oil spill. As a result, another three adjacent tanks of RVS-5000 type caught fire (Figure 1.5). Fire area was 900 square meters. 248 people and 40 units of equipment were involved in extinguishing operation.

\footnotetext{
*Corresponding author: degaev@inbox.ru
} 


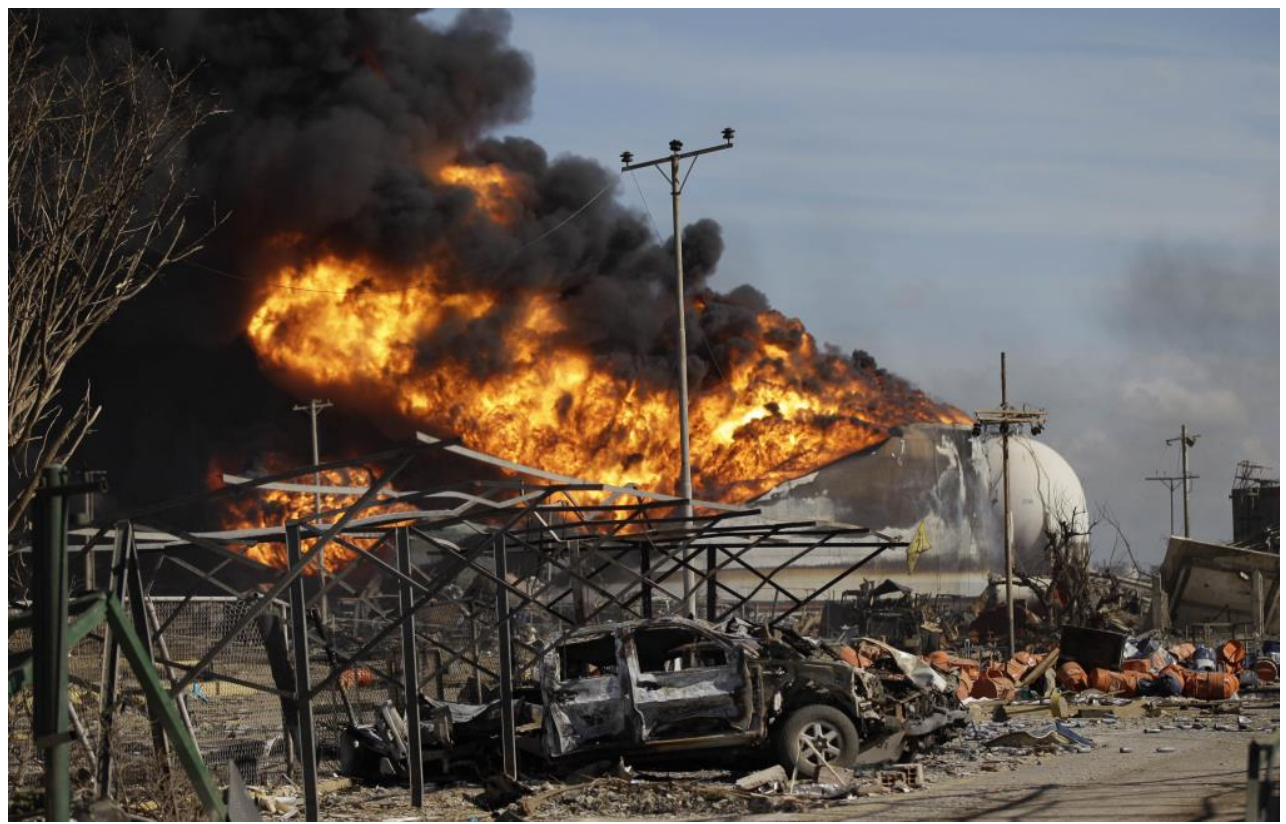

Fig. 1. Fire at the Amuay refinery, Venezuela, 2012

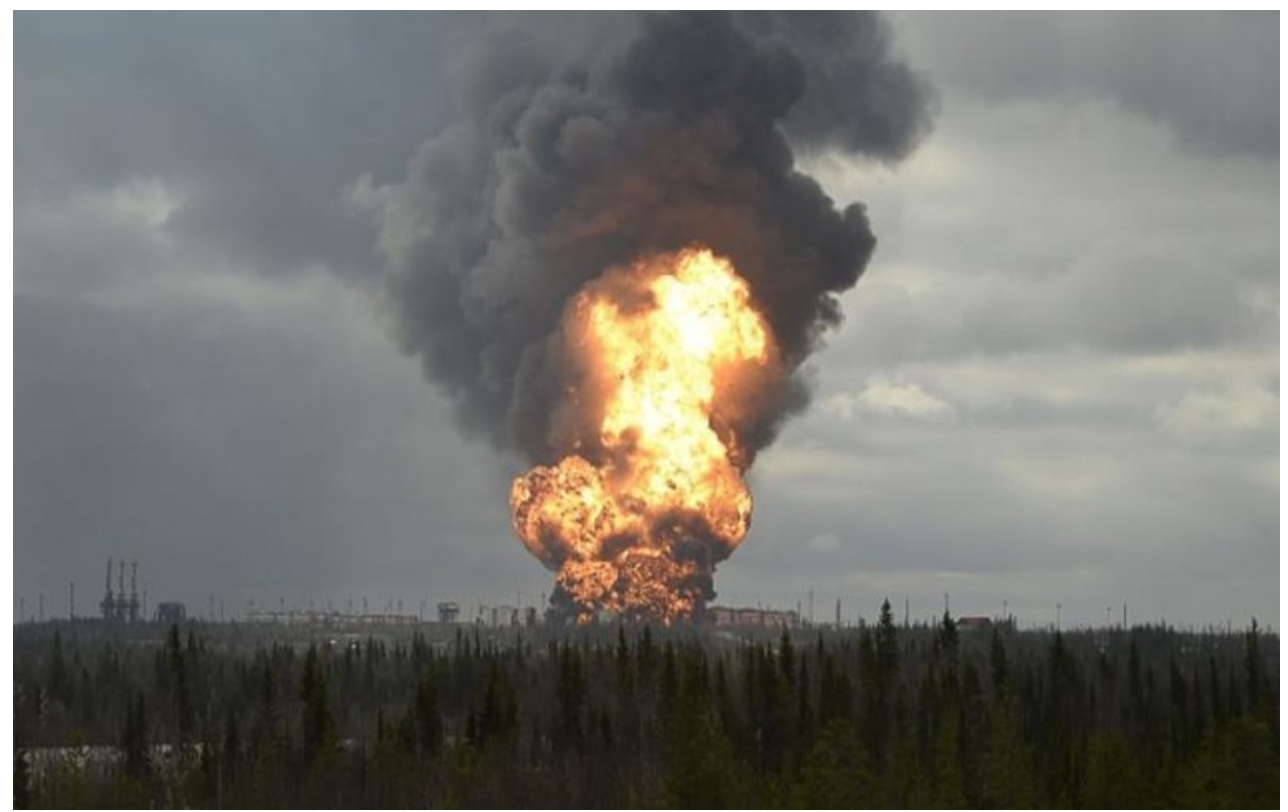

Fig. 2. Fire at the Chamber of Commerce and Industry of Lukoil-Usinskneftegaz, Russia, 2014

Due to many factors and reasons existing fire extinguishing methods and systems did not allow to completely eliminate risks and provide fire safety at the said facilities.

Design errors and defects, as well as unsatisfactory operation and safety retrenchment policy result in extremely low reliability of such systems and eventually in devastating impacts [3-11]. 


\section{Results and Discussion}

Numerous patents contain descriptions of ways how to extinguish fires at warehouse facilities, specifically at oil product tanks using various extinguishing agents, including powders, solid aerosols, sprayed water and foam, in various situations of its production and use.

Method and arrangement of oil product tank fire protection [1-3] suppose aerosol supply directly, inside the flame, above the burning liquid surface. After additional generators completion, platform thermally decomposes, since the temperature in the area of the said platform remains quite high for some time. To eliminate small fire seats, a fire extinguishing agent is supplied from the generators placed permanently at the tank bottom. Aerosol bubbles through the liquid, is cooled and then concentrates inside the flame over the small burning liquid seats surface. As a result, re-ignition seats are extinguished.

Fig. 3 shows a diagram of the fragments illustrating operation of combined fire extinguishing system, which combines subsurface supply of the extinguishing agent and simultaneous supply of aerosol to the liquid burning surface.

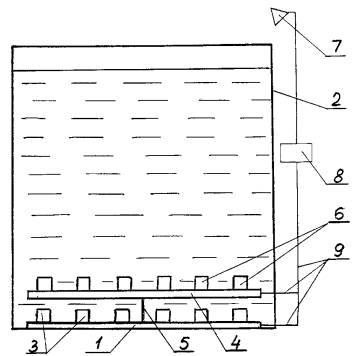

a) the initial state

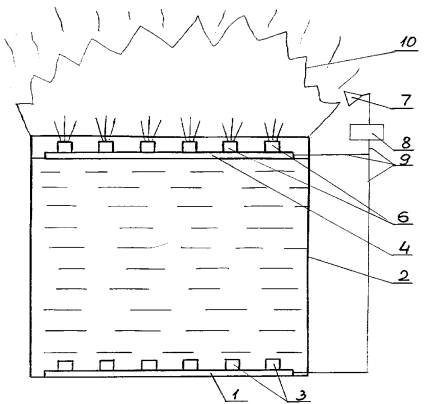

b) the beginning of quenching

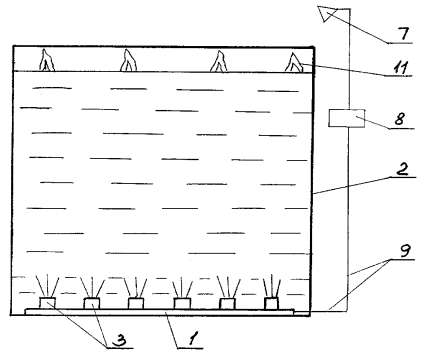

c) the combined feeding

Fig. 3. Diagram of combined fire extinguishing system functioning.

The main point of another method for extinguishing burning liquids in tanks and its arrangement [2-7] is simultaneous supply of an inert gas into the combustible liquid and foaming solution into the liquid above the bubbling inert gas zone (Fig. 4).

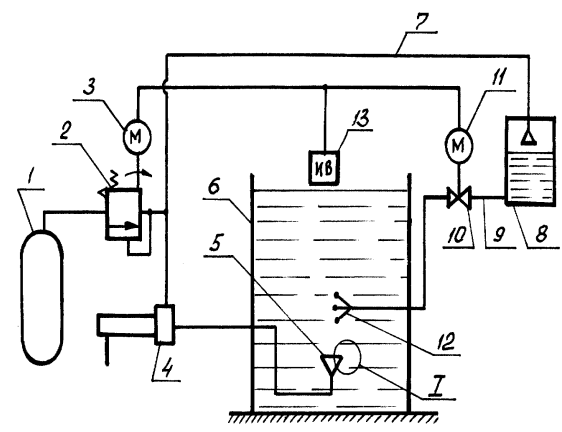

Fig. 4. Diagram of extinguishing burning liquids in tanks including simultaneous supply of a combustible inert gas and foaming solution into the layer.

There is an alternative method of combustible liquids subsurface suppression [8-14], which includes supply of an inert gas through a layer of liquid with simultaneous supply of a sprayed foaming composition onto its mirror. 
Oil product tanks fire protection and fire extinguishing method [12-17] provides for supply of liquid refrigerant to the tank lower part together with oil product and/or through the nozzles installed on the tank bottom, to the oil product surface. Liquid refrigerant is supplied through the floating sprayers. The refrigerant is supplied to the tank upper part through the sprayer installed on the tank roof (Fig. 5).

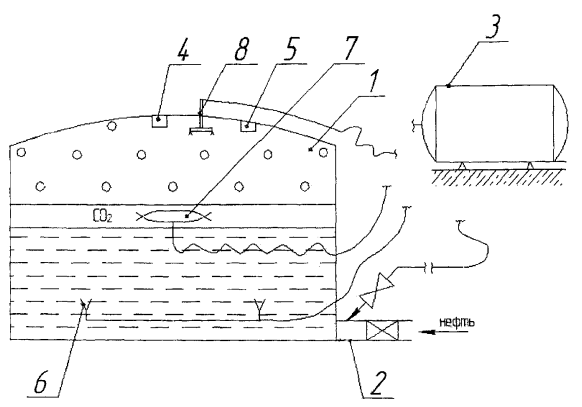

Fig. 5. Diagram of oil product tank fire extinguishing system with the sprayers installed on the tank bottom and roof.

Sequence and duration of refrigerant supply to tank different zones are determined depending on the oil product parameters (temperature, density, etc.) as well as oil and gasair mixture concentration above its surface. The refrigerant is supplied to the tank upper zone in a gaseous or liquid state. Carbon dioxide, nitrogen or a mixture of inert gases can be used as a refrigerant.

The safest method is extinguishing a fire using plunging compact jets of low expansion ratio foam. For this purpose film-forming foams are used, which are prepared based on the aqueous solutions of fluorinated surfactants. Fig. 6 show a diagram of supplying plunging jets of low expansion ratio foam directed to the oil product burning surface.

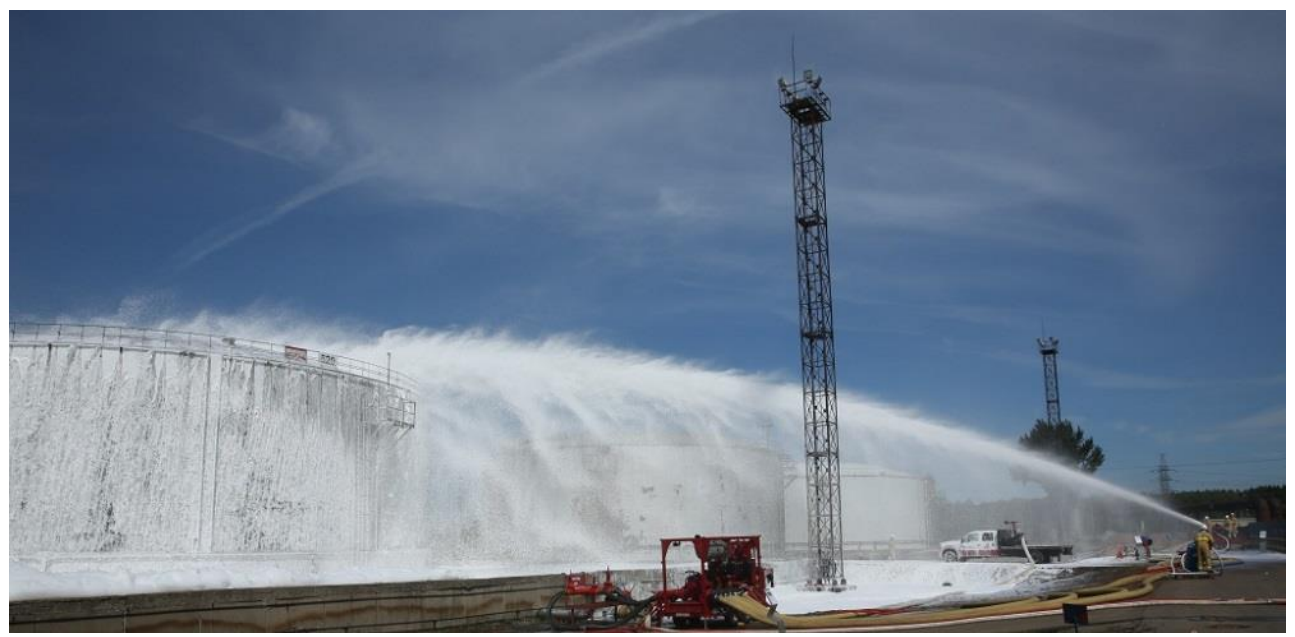

Fig. 6. Feeding of compact foam jet supply from a mobile water monitor to extinguish a fire in the RVS-50000 floating roof tank.

Due to the long flight range, low expansion ratio foam can be supplied from the road and from behind the dike. 
After medium expansion ratio foam generators were put into fire extinguishing practice, it became widely used for fire protection of tanks by supplying foam to the burning oil product surface. Almost every tank has medium or low expansion ratio foam generators on their upper ring. Low expansion ratio foams are prepared based on the fluorinated foaming agents, which do not mix with oil when falling on the top of it.

Today, foam extinguishing is used as main tanks and tank farms protection and extinguishing system. Today, this system is upgraded with self-sustainment conditioned by foam supply to the oil products layer with the help of a pipeline system, which minimizes risk to personnel's life and health. However, the use of fluorinated surfactants, known for their negative impact on the environment, does not rule out environmental risks. On the other hand fluorinated surfactants are less harmful to the environment than the toxic and hazardous substances released during combustion. Therefore, of two evils choose the least [16-24].

\section{Conclusions}

All of the above mentioned extinguishing methods, including foam extinguishing, do not eliminate the risk of fire intensification and propagation to other warehouse facilities completely. Another problem is environmental risk when using existing extinguishing methods. This is due to the fact that fire extinguishing agents used are not ecologically safe and they damage the environment. On the other hand, today it is impossible to extinguish oil products fire at warehouses and tanks without using these substances. Damage is caused not only to the environment, but to the economy as well.

Reducing risks of fires and protecting the environment make it necessary to enhance oil warehouse facilities fire protection by developing new environmentally safe and effective ways of protection and fire extinguishing.

\section{References}

1. A.F. Sharovarnikov, V.P. Molchanov, S.S. Voevoda, S.A. Sharovarnikov, Extinguishing fires of oil and oil products. Izd. house Kalan (2002)

2. V.I. Gorshkov, Extinguishing the flames of flammable liquids. Poznauka (2007)

3. A.H. Baratov, E.N. Ivanov, Firefighting in chemical, petrochemical and petrochemical industries. Chemistry (1971)

4. S.S. Voevoda, V.P. Molchanov, D.L. Bastrikov, M.A. Krutov, Extinguishing fires of motor fuel of the European standard with a low-speed foam. Fire and explosion safety, 20, 4 (2011)

5. D.L. Bastrikov, S.S. Voevoda, V.P. Molchanov, A.F. Shararovnikov, Combined method of extinguishing fires of automobile gasolines in vertical steel tanks. Fire and explosion safety, 23, 6 (2013)

6. D.L. Bastrikov, B.Zh. Bituev, V.P. Molchanov, Application of flexible pipelines in fire protection systems of oil and gas production facilities. Technologies of technospheric security, 58, 6 (2014)

7. V.G. Borkovskaya, E.N. Degaev, I. Burkova, Environmental economic model of risk management and costs in the framework of the quality management system. MATEC Web of Conf., 193, 05027 (2018)

8. Z.M. Xiang, M.L. Guang, L. Chao, Study on Intelligent Fire Fighting System for Large External Floating-roof Tank. International Conference on Intelligent Manufacturing and Materials (2016) 
9. I. Turekova, K. Balog, M. Polka, Effect of firefighting foams on the environment and fire extinguishing. Bezpieczenstwo i Technika Pozarnicza, 25 (2012)

10. D.A. Korolchenko, E.N. Degaev, A.F. Sharovarnikov, Dependence of Fire Extinguishing Efficacy of Low Expansion Foams Solutions Homology Sodium Sulfate on the Molecular Weight of the Surfaceactive Substances. 2nd International conference on material engineering and application (2015)

11. T. Shaefer, B. Dlugogorski, E. Kennedy Sealability Properties of Fluo-rine-Free Fire Fighting Foams. University of Newcastle (2008)

12. V.G. Borkovskaya, Complex models of active control systems at the modern developing enterprises. Advanced Materials Research (2014)

13. V.G. Borkovskaya, Environmental and economic model life cycle of buildings based on the concept of Green Building. Applied Mechanics and Materials (2014)

14. A. Kattge, E.J. Degajev, Der einfluss der höhe der schaumabgabe auf die optimale intensität und den minimalen verbrauch von schaumlöschmitteln. Zeitschrift für Forschung, Technik und Management im Brandschutz, 1 (2016)

15. B.G. Borkovskaya, C.V. Agapov, Standards and fire safety requirements. Fire and Explosion Safety, 11, 23 (2014)

16. E. Degaev, A. Suvorova, A. Suhova, Influence of total head of foam on optimum intensity and minimum particular expense solution size of foamer. IOP Conf. Ser.: Mater. Sci. Eng. 365, 032019 (2018)

17. E. Degaev, V. Razvalyaeva, S. Sabenina, Formation of water film from aqueous film forming foam drops on the surface of oil products. IOP Conf. Ser.: Mater. Sci. Eng. 365, 062037 (2018)

18. Borkovskaya V.G. New requirements professional risks in fire safety. Fire and Explosion Safety, 22, 12 (2013)

19. D.A. Korolchenko, E.N. Degaev, A.F. Sharovarnikov, Determination of the Effectiveness of Extinguishing Foaming Agents in the Laboratory. 2nd International conference on material engineering and application (2015)

20. Degaev E.N. New classification of foaming agents for fire extinguishing. MATEC Web of Conferences 193, 02032 (2018)

21. E.N. Degaev, D.A. Korolchenko, Improving Fire Protection of Pontoon Tanks or Floating Roof Tanks. MATEC Web of Conferences 117, 00036 (2017)

22. E. Korol, N. Shushunova, Green Roofs: Standardization and Quality Control of Processes in Green Construction. MATEC Web of Conferences 106, 06014 (2017)

23. E.A. Korol, S.V. Komissarov, P.B. Kagan, S.G. Arutyunov. The Solution of problems of organizational-technological simulation of building processes. Industrial and civil engineering, 3 (2011)

24. E.A. Korol, A.A. Pleshivtsev, The technology of construction of low-rise buildings from sandwich panels (2017) 